\title{
SOME INEQUALITIES FOR UNIFORMLY LOCALLY UNIVALENT FUNCTIONS ON THE UNIT DISK
}

\author{
YONG CHAN KIM
}

Abstract. In this paper, we will consider some inequalities for a certain subclass $B(\lambda)$ of uniformly locally univalent holomorphic functions on the unit disk in terms of the norm of preSchwarzian derivative. We also investigate the relationships between the class $B(\lambda)$ and the Hardy space.

Mathematics subject classification (2000): 30C45, 30A32.

Key words and phrases: Hardy space, pre-Schwarzian derivative, uniformly locally univalent function.

\section{REFERENCES}

[1] J. BECKER, Löwnersche Differentialgleichung und quasikonform fortsetzbare schlichte Funktionen, J. Reine Angew. Math. 255 (1972), 23-43.

[2] J. BeCKER AND CH. POMMERENKE, Schlichtheitskriterien und Jordangebiete, J. Reine Angew. Math. 354 (1984), 74-94.

[3] M. Bonk, D. Minda And H. Yanagihara, Distortion theorems for Bloch functions, Parcific J. Math. 179 (1997), 241-262.

[4] P. L. DuREN, Theory of $H^{p}$ Spaces, Academic Press, New York and London, 1970.

[5] T. M. FLETT, The dual of an inequality of Hardy and Littlewood and some related inequalities, J. Math. Anal. Appl. 38 (1972), 746-765.

[6] W. K. HaYman, Multivalent Functions, Second edition, Cambridge University Press, London, 1994.

[7] I. B. Jung, Y. C. KIM AND H. M. SRIVASTAVA, The Hardy space of analytic functions associated with certain one-parameter families of integral operators, J. Math. Anal. Appl. 176 (1993), 138-147.

[8] H. O. KIM, Derivatives of Blaschke products, Parcific J. Math. 114 (1984), 175-190.

[9] Y. C. Kim, S. H. LeE AND H. M. SRIVASTAVA, Some properties of convolution operators in the class $\mathscr{P}_{\alpha}(\beta)$, J. Math. Anal. Appl. 187 (1994), 498-512.

[10] Y. C. KIM AND S. SUGAWA, Growth and coefficient estimates for uniformly locally univalent functions on the unit disk, Rocky Mountain J. Math. 32 (2002), 179-200.

[11] Ch. Pommerenke, Linear-invariante Familien analytischer Funktionen I, II, Math. Ann. 155 (1964), 108-154, ibid. 156(1964), 226-262.

[12] СH. Pommerenke, Schlichite Funktionen und analytische Funktionen von beschränkten mittler Oszillation, Comment. Math. Helv. 52 (1977), 591-602.

[13] CH. PommerenKe, Boundary Behaviour of Conformal Maps, Springer-Verlag, 1992.

[14] S. YAMASHITA, Banach spaces of locally schlicht functions with the Hornich operations, Manuscripta Math. 16 (1975), 261-275.

[15] _ Almost locally univalent functions, Monatsh. Math. 81 (1976), 235-240.

[16] Lectures on Locally Schlicht Functions, Mathematical Seminar Notes, Tokyo Metropolitan Univ., 1977. 